\title{
La gestión del patrimonio cultural: políticas de intervención en el Nordeste de Brasil y Andalucía
}

\author{
EMILIO LUQUE AZCONA* \\ SÍLVIA HELENA ZANIRATO**
}

\begin{abstract}
Resumo: O texto aborda possibilidades de gestão do patrimônio cultural do Nordeste brasileiro, tomando como referência experiências desenvolvidas na Andaluzia, região sul da Espanha. Para tanto nos detemos nas cidades de Salvador e Recife que abrigam um relevante patrimônio natural, cultural e edificado, e avaliamos até que ponto esses bens podem gerar benefícios para o desenvolvimento sustentável da região.
\end{abstract}

Abstract: The text approaches possibilities of administration of the cultural heritage of the Brazilian Northeast, taking as reference experiences developed in Andalusia, south area of Spain. We analyzed the cities of Salvador and Recife that shelter a relevant patrimony natural, cultural and built and we evaluated to what extent those goods can be generating of benefits for the maintainable development of the area.

Palavras-chave: Patrimônio cultural. Reabilitação. Conservação integrada.

Key words: Cultural heritage. Rehabilitation. Integrated conservation.

\section{Brasil: un paraíso tropical soñado}

La idea de un espacio de naturaleza exuberante, con playas paradisíacas y selvas impenetrables; habitado por personas sensuales de carácter alegre que bailan bossa nova y samba, beben kaipiriña y son amantes del fútbol, constituyen elementos que generalmente hacen atractivo a Brasil como lugar en el que pasar unas vacaciones. A lo largo del año 2003 fueron concretamente

Doctor en Historia, Universidad Pablo de Olavide, Sevilla, España. E.mail: fihca@dhuma.upo.es

* Doutora em História, Universidade Estadual de Maringá, PR, Brasil. E.mail: sizani@uol.com.br

Estudos Ibero-Americanos. PUCRS, v. XXXI, n. 2, p. 155-175, dezembro 2005 
más de cuatro millones los turistas que visitaron dicho país, un $8,12 \%$ más que en el $2002 .{ }^{1}$

La propaganda turística que invita a conocer este destino tanto la elaborada por los grandes tour-operadores internacionales para ser distribuida por las agencias de viajes, como la realizada por organismos estatales y locales en los puntos de destino, enfatizan la idea de Edén o paraíso reducida a ciertos atributos climáticos, en el que es posible escapar de la rutina de lo cotidiano. ${ }^{2}$ Esta visión, generalizada con el desarrollo del turismo de masas aparecido con las mejoras sociales alcanzadas por los trabajadores de los países más desarrollados o los avances en los medios de transportes, hunde sus raíces en construcciones simbólicas que han estado presentes desde los tiempos de la colonización. ${ }^{3}$

Las ciudades del país en cambio, a pesar del interés patrimonial que muchas presentan y de la oferta cultural y de ocio que ofrecen, son por lo general las grandes ausentes, salvo en casos contados como los de Río de Janeiro, de la que se muestran sobre todo sus playas y morros, o San Pablo, exportada como un destino atractivo para la celebración de negocios y convenciones.

La mayor parte de las propuestas ya no tienen a Río de Janeiro como principal destino turístico, como sucedía años atrás. Desde hace pocos años es el Nordeste del país, región que registra los índices nacionales más elevados de pobreza y en la que se espera que el turismo contribuya a impulsar su desarrollo, para lo cual cuenta con importantes potenciales. Entre ellos el rico legado cultural allí existente, un recurso que podría permitir la superación del actual planteamiento monoproductivo de sol y playa que tan malos resultados han generado en otras zonas del planeta (expulsión de las poblaciones autóctonas de sus pueblos, ruptura del tejido social a escala local y especulación del suelo, erradicación de zonas agrícolas o dependencia externa entre otros). ${ }^{4}$

1 Datos aportados por EMBRATUR www.embratur.gov.br (capturados en 7 de mayo de 2004) y por OPOVO-Jornal do Ceará, Fortaleza (formato digital), $<$ www.noolhar.com/opovo/> (capturado en 19 de mayo de 2004).

2 Para la elaboración de la presente investigación hemos consultado las paquetes turísticas ofertadas en catálogos y a través de las webs de las siguientes agencias de viajes: Halcón Viajes, Viajes El Corte Inglés, Barceló Viajes, Viajes Caja San Fernando y Viajes Marsans.

3 HIERNAUX, Daniel \& CORDERO, Nicolás Allen. Imaginarios sociales y turismo sostenible. Costa Rica: Facultad Latinoamericana de Ciencias Sociales (FLACSO), 2002, p. 25.

4 KADT, Emanuel de. Turismo, ¿pasaporte al desarrollo? Madrid: Ediciones Endimión, 1991, p. 10. 

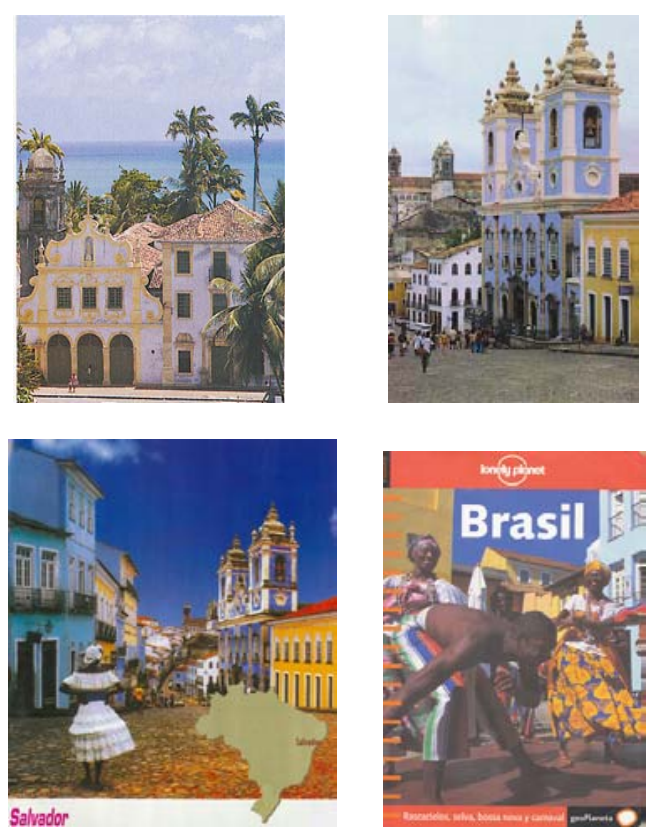

Olinda (izquierda) y Salvador de Bahía en el catálogo que la agencia Traveplan dedica a Brasil para la temporada 2004. A la derecha portada de la guía Lonely Planet, del año 2002.

En los folletos turísticos distribuidos por agencias de viajes se observa por tanto la escasa oferta de un turismo cultural, y cuando éste aparece se basa principalmente en hitos patrimoniales de carácter arquitectónico y monumental, con ausencia de elementos como la gastronomía, el folklore (con excepción del Carnaval) o la artesanía.

\section{El patrimonio urbano nordestino: \\ una relevante herencia cultural}

El Nordeste de Brasil posee numerosos pueblos y ciudades que preservan un rico legado patrimonial y cultural, visible en antiguos y ostentosos edificios que nos hablan de los tiempos de la colonización portuguesa y de los diferentes lenguajes arquitectónicos y urbanísticos incorporados a lo largo de los siglos XIX y principios del XX. Junto a ello, su variada y rica gastronomía, el folklo- 
re y la religiosidad de sus gentes, donde se mezclan elementos de muy diverso origen, tanto africano, como indígena y europeo, constituyen atractivos de indudable interés para el fomento de un turismo cultural. En este apartado vamos a centrarnos en el estudio del importante legado patrimonial de las capitales de los estados de Pernambuco y Bahía, las ciudades de Recife y Salvador, aspecto que nos permitirá una mejor comprensión de las actuaciones llevadas a cabo para la rehabilitación de sus centros históricos de cara al fomento de la actividad turística.

Salvador de Bahía, capital del Brasil colonial desde 1549 a 1763 y principal puerto, se conformó durante ese período como el principal centro urbano de las posesiones ultramarinas de Portugal, pasando de los quinientos habitantes que tenía en 1584 a los más de treinta y nueve mil del año $1780.5^{5}$ Consolidada durante muchos años como el más grande mercado brasileño de esclavos, la ciudad contaba por ello en los tiempos de la colonia con el principal porcentaje de población negra de Brasil, siendo para el siglo XIX la mayor parte de sus habitantes esclavos o gentes que habían logrado salir de tal condición. ${ }^{6}$ Junto a estos, inmigrantes portugueses y los holandeses que tomaron la ciudad en mayo de 1624, conformaron los principales contingentes de población durante el período colonial.

La ciudad de Recife alcanzaría también momentos de esplendor, en su caso tras consolidarse como puerto de las ricas plantaciones de azúcar de los alrededores de Olinda a lo largo del siglo XVII. Esta situación se vio favorecido por las características naturales de su emplazamiento, en el que destacan los canales que forman los cursos de varios ríos hacia su desembocadura, situación por la que se le ha considerado como la "Venecia de Brasil", y los arrecifes que se encuentran mar adentro.

Estos momentos de esplendor durante la colonia, que en la zona del Nordeste se dio en diferentes momentos y lugares a partir del ciclo del palo Brasil, el cultivo de la caña de azúcar y el tabaco, la ganadería o la extracción de diamantes, ${ }^{7}$ permitieron, a diferencia de otras zonas del territorio brasileño, un desarrollo urbano y arquitectónico importante. Salvador concretamente, tuvo un des-

5 CERRILLO, Maria L. (coord.). Historia Urbana de Iberoamérica: a Ciudad Iberoamericana hasta 1573. Madrid: Comisión Nacional del Quinto Centenario, Consejería de Obras Públicas y Consejo Superior de los Colegios de Arquitectos de España (tomo III - 1), 1987, p. 258-259.

6 MATTOSO, Kátia M. de Queirós. Bahia: a Cidade de Salvador e seu Mercado no Século XIX. São Paulo: Hucitec, Secretaria Municipal de Ed. e Cultura, 1978, p. 201.

7 CERRILLO, La ciudad..., p. 255. 
envolvimiento urbano y poblacional en dos planos, determinado por las características de su asentamiento, con una serie de barrios que se agruparon conformando las denominadas "cidade baixa" y "cidade alta", la primera ligada a las actividades portuarias y la de arriba de la barranca a las administrativas y defensivas. ${ }^{8}$

En los planos y perspectivas realizadas en la época se aprecia como la parte alta quedaba en sus inicios limitada a un trapecio amurallado, edificado entre la Misericordia, la plaza Castro Alves y los alrededores de la actual calle Rui Barbosa, y como la trama continuó extendiéndose a la vez que se materializaba un sistema defensivo que incorporaba nuevos baluartes en los puntos más estratégicos. ${ }^{9}$ Con respecto al trazado de las calles y plazas de la zona, se observa una aproximación a las propuestas organicistas medievales con plazoletas, calles de dimensiones diversas y tortuosas, compases, situación característica en las plantas urbanas portuguesas trazadas con anterioridad a las influencias ordenadoras de los ingenieros militares y académicos del siglo XVIII. ${ }^{10}$

En el terreno arquitectónico, por la estrecha vinculación que dicha ciudad mantenía con su Metrópoli, la transferencia cultural lusitana fue directa hasta que en el siglo XVIII se introdujeron nuevas formas de expresión, como la que aparece en la iglesia de la Orden Tercera de San Francisco, un barroco hispanoamericano en el que se integran rasgos "mestizos". ${ }^{11}$ En este período se construyeron muchos de los templos que en la actualidad se encuentran diseminadas por numerosos puntos de la ciudad, uno para cada día del año según la creencia popular, entre los que destacan algunos como el Convento de San Francisco, la Iglesia de la Compañía de Jesús (hoy Catedral), la Iglesia y el Convento de N. S. do Carmo, el Convento de São Bento, el de Santa Teresa, la Iglesia Matriz do Santísimo Sacramento o la Iglesia de Nuestra Señora do Rosario dos Pretos, entre muchos otros. ${ }^{12}$ El barrio del Pelourinho, localizado en la zona alta de la ciudad, concentra gran parte de los vestigios que nos hablan del pasado esplendoroso de la que fuera capital colonial.

8 TAVARES, Luís Henrique. História da Bahia. São Paulo, UNESP, 2001, p. 70-73.

9 REIS, Nestor G. Imagens de vilas e cidades do Brasil colonial. São Paulo: Edusp, 2001, p 16-53.

10 GUTIÉRREZ, Ramón. Arquitectura y Urbanismo en Iberoamérica. Madrid: Cátedra, 1997, p. 100.

11 GUTIÉRREZ, Arquitectura..., p. 70.

12 ALMEIDA COUTO, Adriana. Centro Histórico de Salvador, Bahía, Brasil: patrimônio mundial. São Paulo: Horizonte Geográfico, 2000, p. 64-87. 
La ciudad de Recife presentaba, a diferencia de la anterior, un modelo totalmente planificado sobre una zona pantanosa en la que se tuvieron que hacer importantes trabajos de infraestructura. En esa época destacaría por su singularidad el trazado de callesmuelle y canales que se conformaron en importantes arterias comerciales, relegándose con ello a la plaza a un papel de menor relevancia. ${ }^{13}$ En ella se levantaron también imponentes templos que exhiben una rica arquitectura y decoración barroca, entre los que destacan algunos como las iglesias de Santo Antônio, la de N. S. do Carmo o la de N. S do Rosário dos Pretos entre otras. Es especialmente destacable por su altar en talla revestida de oro y las bellísimas pinturas del techo la Capela Dourada que se integra en el conjunto de construcciones erigidas por los franciscanos entre los siglos XVIII y XIX. Otros edificios relevantes que se construyeron también durante el período colonial fueron el de la sinagoga, erigida en el siglo XVII y considerada como "la primera de las Américas"; el conocido en la actualidad como "la Alfândega", inicialmente utilizado como convento y después como almacén; u otros de carácter militar como el Forte do Brum (1629) o el Forte das Cinco Pontas (1630).

A lo largo del siglo XIX ambas ciudades experimentaron cambios importantes en sus paisajes urbanos y arquitectónicos, siendo varias las plazas y avenidas que se embellecieron con jardines, fuentes y esculturas que trataban de recrear paisajes similares a los parisinos o londinenses. Asimismo, las epidemias de mediados de siglo obligaron a poner en práctica medidas que mejoraran las deficitarias condiciones de salubridad e higiene existentes, hecho que contribuyó al crecimiento de población, que para el caso de Salvador significó multiplicar por cuatro su número de habitantes hasta alcanzar la cifra de 205 mil habitantes en el año 1900.14

En el terreno arquitectónico, la arquitectura académica y ecléctica decimonónica que definió el carácter de muchas ciudades latinoamericanas, dejó también su impronta en los principales núcleos urbanos del Nordeste brasileño. Aquí, como en otras partes del continente, los ingenieros militares llevaron a inicios del siglo la impronta del clasicismo británico, claramente manifiesto en la fachada de la Asociación Comercial de Salvador que diseñara el portugués Cosme Damian da Cunha (1815), destacando con este estilo otras obras como el cementerio del Pilar o la Alfándega con

13 CASTRO, Josué de. Um ensaio de Geografia Urbana: a cidade de Recife. Ensaios de geografia urbana. São Paulo: Brasiliense, 1957, p. 197.

14 ALMEIDA COUTO, Centro...., p. 28. 
su cuerpo circular en la misma ciudad, o en Recife algunas como el Teatro Santa Isabel o la sede actual de la Academia Pernambucana de Letras. ${ }^{15}$

Junto a estos se irían levantando posteriormente imponentes edificios públicos como el Palacio de Río Branco de Salvador de inicios del siglo XX, construido sobre el que fuera Palacio de los Gobernadores Generales de Brasil del siglo XVII; o el Congreso de Pernambuco, que al igual que el anterior se hizo con cúpula central de tambor alto, destacando en esta última ciudad otros como la Torre Malakoff de la década de 1850, usada como observatorio astronómico. Con respecto a la arquitectura doméstica, las viviendas coloniales sufrirían importantes transformaciones por varios motivos: las reformas higienistas que buscaban una mayor ventilación e iluminación natural de los interiores y la llegada de nuevos materiales de construcción tras la apertura del mercado brasileño a las naciones amigas en 1808.16 A partir de las décadas finales del siglo XIX se fueron incorporando nuevos estilos arquitectónicos de inspiración europea en las fachadas de residencias de nueva planta.

A lo largo del siglo XX los barrios más antiguos de Salvador y Recife continuaron experimentando importantes cambios en la composición de su vecindario tradicional y en las funcionalidades desempeñadas. En la década de 1930 el Pelourinho pasó a convertirse en una zona proletaria, al abandonar la aristocracia sus casonas del barrio para instalarse en los ensanches de la ciudad. ${ }^{17} \mathrm{El}$ estado de los inmuebles comenzó a deteriorarse a medida que los residentes, muchos de ellos sin título de propiedad, no podían invertir en la conservación de los que ocupaban.

El caso del barrio de Recife Antiguo fue diferente, ya que durante la década de 1910 experimentó una intensa intervención urbanística con la que se configuró una nueva red viaria, se rompió el istmo original dando origen a la "Ilha do Recife" y se expandieron las instalaciones portuarias. Todo ello demoliendo conjuntos edilicios de importante valor histórico que se sustituyeron por nuevos de estilo ecléctico, y expulsando a sus tradicionales moradores, perdiendo con los años el barrio su carácter residencial con una presencia más acentuada del capital financiero nacional e internacional. El proceso de descentralización funcional vivido entre

15 GUTIÉRREZ, Arquitectura..., p. 396 y 400.

6 ALMEIDA COUTO, Centro..., p. 49.

17 MATOS, Waldemar. Evolução histórica e cultural do Pelourinho. Salvador: SENAC/BA, 1978, p. 28. 
los años 50 y 70 expulsaría el centro económico a otros puntos de la periferia urbana de Recife, siendo esta una etapa más que originaría gran parte de los actuales problemas de marginalidad que presenta la zona. ${ }^{18}$

\section{Políticas públicas para la rehabilitación de sus centros históricos}

A pesar del abandono del Centro Histórico de Salvador a lo largo de casi todo el siglo XX, existió finalmente un reconocimiento del valor cultural de aquel espacio, comenzando en 1983 los estudios junto a UNESCO para elevarle a la condición de Patrimonio de la Humanidad. Se catastraron los principales monumentos históricos e inmuebles y en diciembre de 1985, el Centro Histórico de Salvador fue declarado Patrimonio Cultural de la Humanidad. Investigaciones y levantamientos efectuados en aquella ocasión constataron que 305 inmuebles localizados en el área relevada estaban completamente arruinados, o en estado avanzado de deterioro físico. ${ }^{19}$

Ese espacio en ruinas abrigaba una población compuesta por jóvenes, en su mayoría negros y mestizos que vivían de trabajos temporales y eran extremamente pobres.

Al inicio de las obras de recuperación en julio de 1992, esa población residente fue retirada del lugar mediante indemnizaciones forzadas y, en la mayoría de los casos, transferida para otros barrios de la ciudad. El gobierno de Bahía, responsable del planeamiento y ejecución de los trabajos de rehabilitación del local, se volvió propietaria de los inmuebles que estaban abandonados y que fueron expropiados (30\% del total). Por medio de anticipos pasó a detener el derecho de uso de las edificaciones particulares $(70 \%)$ por un período comprendido entre los cinco y los diez años. Con ese poder pasó a definir el perfil de las actividades deseadas, el uso del suelo y quién podría instalarse en el Centro de Salvador. ${ }^{20}$

Toda la responsabilidad para la gestión del espacio quedó a su cargo, pasando a proveer los servicios de infraestructura - ma-

18 CASTRO, Um ensaio..., p. 268.

19 BOMFIM, J. Políticas Públicas para o Centro Histórico de Salvador. Salvador: UFBA, 1994 (dissertação de mestrado em Arquitetura), p. 72.

20 URIARTE, U. M. Intervenções recentes em centros históricos. Artigos CeVEH. Disponível em www.ceveh.com.br/biblioteca/artigos/um-p-a-intervenc.html (capturado em 28.2.2003). 
nutención hidráulica, eléctrica, servicios de pinturas de fachadas y reparación de paredes - así como la organización y publicidad de los eventos culturales. ${ }^{21}$

La eliminación del uso residencial fue justificada con alegaciones de que la población residente era incompatible para el desenvolvimiento del turismo y la preservación de los inmuebles. Según el gobierno de Bahía, la preservación no podría realizarse por los antiguos ocupantes en la medida en que se trataba de personas "sin condiciones económico-culturales de conservarlo". ${ }^{22}$

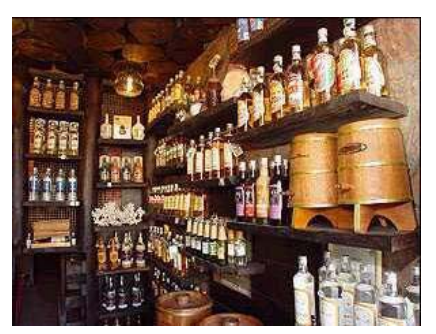

Bebidas del Pelourinho

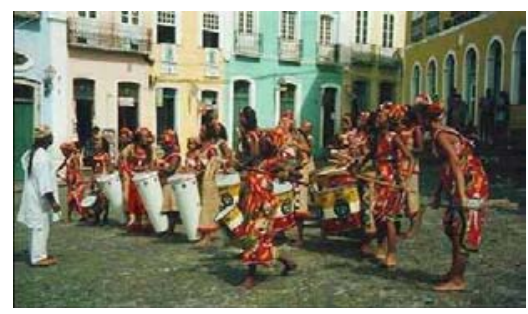

Banda Didá, Grupo de percusión

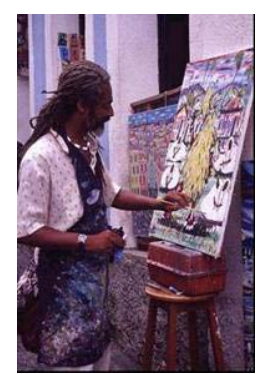

....Pintor local

Consultar Sitio imagenes de Salvador www.bahia-online.net/ Pelourinho.htm

La opción del gobierno del Estado para la recuperación del conjunto arquitectónico en detrimento de lo cultural y social acarreó consecuencias para el mantenimiento de la restauración, sobre todo en cuanto a la posibilidad de convertir al Centro Histórico de Salvador en sustentable, es decir, con capacidad de proveer los

21 FERNÁNDEZ, A. S. A. Empresarialismo urbano em Salvador. A recuperação do Centro Histórico Pelourinho. Dissertação de Mestrado em Arquitetura. UFPE, Recife, 1998, p. 54-55.

22 ZANIRATO, Silvia Helena. As políticas de preservação e de usufruto do patrimônio Cultural: o Centro Histórico de Salvador como um estudo de caso. Revista Pós História, Assis-SP, vol. 10, 2002, p. 161-180. 
recursos que necesita. Esa situación se volvió de tal forma comprometedora que hoy, "retirada la participación del Estado, el Centro Histórico no se sustenta y corre serio riesgo de volverse a degradar". ${ }^{23}$

Por su parte, la ciudad de Recife vive una situación algo diferente en lo que concierne a la aplicación de medidas destinadas a la conservación de su patrimonio cultural.

El centro histórico de la ciudad comprende a un conjunto de barrios: Recife Antiguo o Isla de Recife, San Antonio, San José y Boa Vista. El Barrio de Recife es la porción más antigua de la ciudad y su historia está marcada por el proceso de abandono poblacional sufrido a partir de la década de 1930, así como por el deterioro de sus infraestructuras urbanas. Los demás barrios que componen la zona central, a su vez, sufrieron mudanzas que interfirieron en la calidad de vida, pues se convirtieron en áreas de concentración de poblaciones de baja renta, de comercios de productos de primera necesidad y de proliferación de vendedores ambulantes.

A partir de 1986 la Prefectura de Recife decidió intervenir en el centro con el objetivo de contener el proceso de degradación de aquel espacio, sin bien las acciones fueron puntuales como la recuperación de algunos bienes considerados de significativo valor histórico. Aún así, hasta fines de la década de 1980 el Centro de Recife permanecía como una de las principales áreas problemáticas de la ciudad. Dentro del mismo, el Barrio de Recife Antiguo llamaba la atención por la degradación física de las edificaciones y de los espacios públicos y por la ausencia de moradores, constituyéndose en un área estigmatizada, una zona "marginal" y peligrosa. Fue entonces cuando el gobierno municipal elaboró una estrategia para intervenir en el proceso de degradación del Centro.

Se formuló un Plan de Revitalización con el objetivo de conservar el patrimonio histórico y cultural del barrio y convertirlo en un espacio de ocio y diversión para la población de la ciudad. En ese plano el turismo aparecía como un recurso potencial para el desenvolvimiento de una actividad destinada a generar riqueza y empleo, al contar el Barrio con un patrimonio arquitectónico de inestimable valor en el ámbito nacional y un emplazamiento en un enclave natural magnífico, justamente por tratarse de una isla delimitada por ríos y por mar, con atributos ambientales únicos.

23 SIRCHARL, IV Encontro, 2001. Análise do caso Salvador frente aos três eixos temáticos. Disponível em

http://www.archi.fr/SIRCHAL/seminair/sirchal4/frameDiagVPT.htm (capturado em 9.11.2003). 
La Prefectura buscó asociaciones con empresas privadas para la rehabilitación y el mantenimiento del cuidado de las plazas del Barrio. La inversión privada fue significativa llegando a alcanzar la proporción de uno a uno. La mayoría de los recursos públicos fueron garantizados por la Prefectura de la Ciudad, con una pequeña participación del Gobierno del Estado. ${ }^{24}$

Las obras iniciales para la rehabilitación del Barrio de Recife incidieron en la infraestructura física del local: remodelación de las calles, de los puestas, de las calzadas y de la iluminación. En seguida se procuró la recuperación de las plazas y de las fachadas de los edificios. El tercer momento fue la consolidación de áreas dentro de ese espacio para el emprendimiento del turismo. Con eso el Barrio de Recife Antiguo pasó a ser un espacio de atracción de eventos de orden cultural como el Carnaval, o de grandes shows, concebidos dentro de un calendario que contemplaba, en gran parte, actividades turísticas.

En 1997 se inició el cuarto momento, con proyectos para un turismo de negocios, buscando atraer inversiones y empresas de alta tecnología.
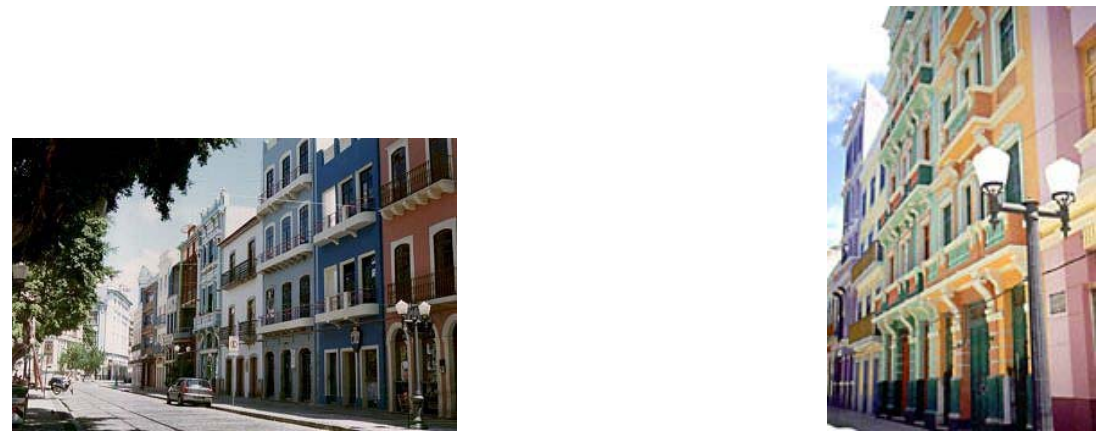

Vistas parciales de la Calle Bom Jesús en el Barrio de Recife Antiguo.

A pesar de ello, no se puede decir que la restauración emprendida en ese espacio haya sido un éxito, sobre todo cuando se piensa en la participación de la comunidad local durante su proceso de implementación. Justamente en ese aspecto pueden percibirse los problemas que han puesto de manifiesto los límites del emprendimiento.

24 ZANCHETI, Sílvio M. \& LACERDA, Norma. A revitalização de áreas históricas como estratégia de desenvolvimento local: avaliação do caso do Bairro do Recife. Recife: Ed. Universitária-UFPE, 1998. 
Como el Centro Histórico de Salvador, los edificios del Barrio de Recife poseen varias plantas, pero solamente la baja, la fachada y los tejados sufrieron reparaciones significativas. La mayor parte de los inmuebles pasó a desempeñar una única actividad bajo un régimen de contrato único, siendo escasos los que lograron desempeñar usos diversificados. En ambos procesos el incentivo para la reforma de las edificaciones persiguió el convertirles en espacios para el abrigo de actividades lucrativas, capaces de atraer consumidores para el área. Se buscó una población fluctuante de turistas o usuarios temporários (principalmente a la noche), estrategia que terminó por ser inadecuada una vez que el turismo no garantizó el retorno de la inversión, permaneciendo ambos lugares dependientes de las partidas desembolsadas por el poder público para la manutención del patrimonio arquitectónico recuperado.

Por otra parte, es necesario destacar como el patrimonio de una ciudad no se agota en sus edificios ni en su paisaje urbano. Las manifestaciones culturales inmateriales, gestionadas al largo de su proceso de formación histórico como la gastronomía, la artesanía, las tradiciones religiosas, las fiestas paganas, forman parte de su conjunto. Tales manifestaciones sustentan la identidad colectiva de los habitantes y forman parte de la cultura de la ciudad en sentido amplio y no pueden ser renunciadas cuando se piensa en políticas destinadas la preservación del patrimonio histórico y cultural. ${ }^{25}$

El Centro de Salvador, reconocido por el conjunto edificado de innegable valor, se volvió también notorio desde mediados del siglo XX por las prácticas y representaciones culturales de la población que allí habitaba y que producía significados y atribuía una identidad específica al local. La musicalidad de grupos como Afoxé Filhos de Gandhi u Olodum le configuraban como un local que valoraba la tradición africana de los antepasados de la población residente, lo que contribuía a la atracción de personas identificadas con el sonido y con el movimiento negro. Del mismo modo, la gastronomía era un polo de atracción de aquellos que se interesaban en saborear bebidas como el cravinho, o platos como el vatapá, acarajé o xinxin de galinha, símbolos de la ancestralidad africana.

También las actividades de serigrafía, incluyendo el aspecto creativo (diseño) y arte-final (revelación/estampa), caracterizaban formas específicas de apropiación y representación de aquel espacio, estampado en vestimentas y adornos que remitían a los orígenes africanos de la población habitante del lugar. Cabe también

25 CALLE VAQUERO, Manuel de la. La ciudad histórica como destino turístico. Barcelona: Editorial Ariel, 2002, p.60. 
destacar la pintura en estilo naif, pinturas "ingenuas" de las moradas de familia y de las moradas de prostitución, de bares y de caminos de piedra por donde circulan vendedores ambulantes, bohemios, mendigos, hombres, mujeres, etc., que traducían modos de la población residente mirar y representar aquel espacio.
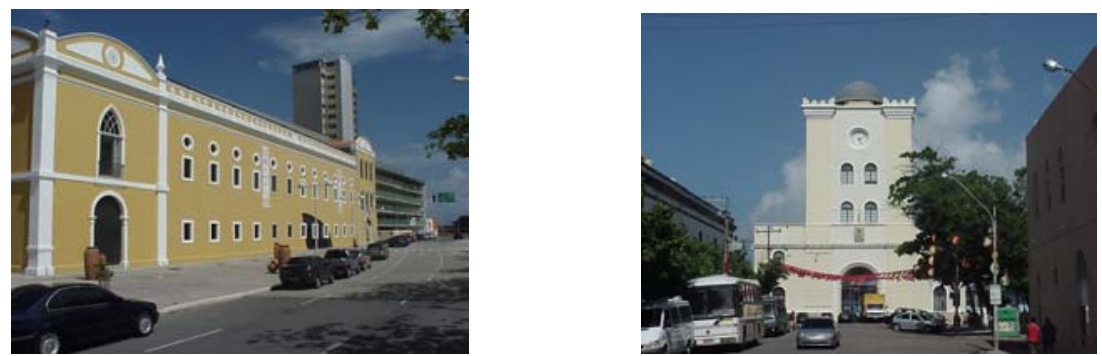

La antigua Alfándega, convertida en un moderno Centro Comercial, y la Torre Malakoff.

Fotos de Zanirato, Silvia Helena.

Con eso queremos decir que el patrimonio no es solamente materia física, es también conocimientos, perícias, varios tipos de desempeños tradicionales y tradiciones orales presentes en los espacios. Un espacio considerado patrimonio cultural debe ser el resultado de la combinación armoniosa de construcciones firmes o de las ruínas, con el paisaje y con las actividades humanas allí desenvueltas. Su autenticidad se asienta tanto en la materialidad expresa en el conjunto, como en la creatividad y los significados culturales de usos y funciones de ese conjunto. 26

La misma cuestión se aplica al Centro de Recife. Su patrimonio cultural puede encontrarse en las antiguas iglesias, en los fuertes, en los casarones y en otras edificaciones históricas, pero igualmente en los eventos y manifestaciones populares como la artesanía y la gastronomia, sin contar el carnaval, la mayor fiesta popular de aquella ciudad. Las danzas de origen africano e indígena: maracatu, caboclinha, frevo y los blocos carnavalescos traducen modos únicos de expresar la musicalidad y el bailado de la población de Recife.

La riqueza del patrimonio cultural de los centros de las ciudades de Salvador y de Recife deriva de la trayectoria histórica de esos lugares, de la acumulación de sucesivos modos de vivir que

26 JOKILEHTO, J. Conceitos e idéias sobre conservação. In: JOKILEHTO, J. et al. Gestão do patrimônio Cultural Integrado. Recife: Ed. Universitária-UFPE, 2002, p. 14. 
determinaran su valor como locales urbanos singulares. Ese legado de tradiciones no puede ser pensado separadamente cuando se busca la revitalización de esos espacios.

Para que la conservación del patrimonio revitalizado en Salvador y en Recife pueda ser sustentable es necesario pensar en usos mixtos para esos locales, con el retorno de moradores que posibilite consolidar una vida cotidiana, con varias actividades. La revitalización pretendida requiere habitar la ciudad, conseguir la permanencia de los antiguos habitantes, la atracción de nuevos grupos sociales y la manutención de las actividades tradicionales de la ciudad.

El centro histórico no puede ser visto como una mercadería sujeta a procesos especulativos, como valor de cambio más que valor de uso. Las políticas de revitalización de los centros históricos no pueden generar la desaparición de sus habitantes y sus actividades productivas. Estos deben conformar espacios sociales de cultura y vida y no una mercancía cuya rentabilidad se incremente sin límite alguno. Hay que pensar las formas por las que el patrimonio cultural puede ser explorado para la generación de divisas que permitan el desenvolvimiento de la ciudad. El turismo cultural, o sea, la exploración de las bellezas naturales y artísticas, así como de las tradiciones y costumbres de las personas que habitan esos parajes, se ha convertido en un medio de desenvolvimiento económico, al que los pueblos, en especial los que se encuentran en vías de desarrollo, no pueden renunciar porque constituye una fuente de divisas y de puestos de trabajo. ${ }^{27}$

Claro que no se trata de hacer del centro histórico un parque de exposiciones para ser contemplado por los turistas. Para eso se debe tener en cuenta que ese centro sea un espacio de vivencia y no sólo de visita. Para que ese patrimonio pueda ser explorado de modo sustentable por el turismo es fundamental que se reconozca la importancia de la cultura como una fuerza capaz de impulsar y dinamizar el desarrollo social, de modo que incluya el mayor número de manifestaciones artísticas y de elementos de la cultura popular. ${ }^{28}$

27 HERNÁNDEZ HERNÁNDEZ, Francisca. El patrimonio cultural: la memoria recuperada. Grijón: Ediciones TREA, 2002, p. 375.

28 GREG, Richards. Políticas y actuaciones en el campo del turismo cultural europeo. In: FUNDACIÓN del Patrimonio Histórico de Castilla y León. Turismo Cultural: el patrimonio histórico como fuente de riqueza. Valladolid: FPFCL, 2000, p. 79. 


\section{Andalucía: experiencias en la conservación urbana integrada y promoción turística}

La Comunidad Autónoma española de Andalucía conforma a nuestro parecer un referente de gran interés para el caso del Nordeste de Brasil en lo que respecta a políticas de conservación urbana integrada y de fomento de turismo cultural. Los fuertes vínculos históricos y culturales que dicha región mantiene con América Latina desde hace más de quinientos años, y sus esfuerzos por ofertar durante los últimos años propuestas alternativas al turismo de sol y playa, con sus aciertos y sus errores, son aspectos que pueden contribuir a la meditación y el intercambio con lo que sucede en la región que analizamos.

Con una superficie que comprende 87.268 kilómetros cuadrados, Andalucía se caracteriza por la variedad de sus paisajes, con contrastes tan acusados como los que conforman el extenso valle del Guadalquivir y las zonas montañosas de Sierra Nevada, o las áreas de extrema sequedad de la provincia de Almería con la de abundantes lluvias de la Sierra de Grazalema, Cádiz. Posee un clima de tipo mediterráneo, caracterizado por sus veranos largos, calurosos y secos, e inviernos cortos y fríos, siendo las escasas precipitaciones más abundantes en otoño.

Poblada desde la Edad de Piedra, durante la antigüedad los fenicios, griegos, cartagineses y romanos dieron cuenta de la región como lugar privilegiado por la naturaleza. Las ocupaciones romana y árabe del territorio dejaron un importante legado cultural y patrimonial que continuaría enriqueciéndose durante la Edad Moderna con la construcción de numerosos palacios, iglesias, catedrales y conventos de estilos gótico, renacentista y barroco, todo ello gracias a los beneficios del comercio americano. En crisis durante el siglo XIX, los viajeros románticos sentirían una gran atracción por sus paisajes y la persistencia de lo árabe, conformando a partir de entonces una imagen estereotipada de Andalucía que persiste hasta nuestros días como tierra de flamenco, gitanos y toreros, tópicos que se extrapolan al resto de España. ${ }^{29}$

A partir de la afluencia masiva de turistas que comenzó a llegar al país a partir de la apertura al mercado exterior en 1959, la Costa del Sol comenzó a convertirse en un referente internacional para el turismo de sol y playa, pasando el litoral onubense, gaditano, granadino y almeriense a recibir turistas nacionales principal-

29 GÓMEZ MENDOZA, Josefina et al. Viajeros y paisajes. Madrid: Alianza Universidad, 1988, p. 52. 
mente. ${ }^{30}$ Junto a sus playas, algunos de los monumentos más emblemáticos de la región, como la Alhambra de Granada, la Mezquita Catedral de Córdoba, o los Reales Alcázares y la Giralda de Sevilla, y festejos como la Semana Santa o las Ferias, han consolidado a estas tres ciudades como destacados destinos turísticos en el interior de la comunidad.

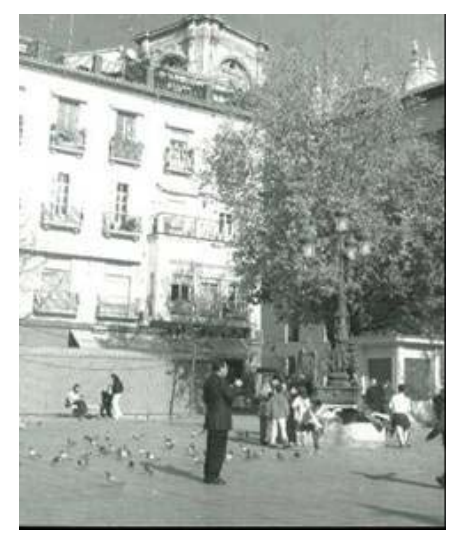

El Albaicín hoy. In INSTITUTO Municipal de Rehabilitación, Ayuntamiento de Granada, Vivir en la ciudad histórica. Granada, Encuadernaciones Olmedo, 2003.

Andalucía recibió más de siete millones y medio de visitantes a lo largo del 2003, cifras que en el ámbito nacional sólo superan Cataluña y Canarias, siendo para ese año más de cincuenta y dos millones y medio los turistas que ingresaron en el país. ${ }^{31}$ Con un porcentaje de su PIB en varios puntos inferior al que le podría corresponder en el contexto español por su población y superficie y una tasa de desempleo bastante superior a la media española, la actividad turística es una de las apuestas del gobierno autonómico para consolidar el proceso de modernización que viene aplicando desde el retorno de la democracia.

Los principales retos que actualmente afrontan los responsables del turismo andaluz, de manera similar a los del turismo del nordeste brasileño, consisten en la necesidad de crear un modelo competitivo que en el largo plazo preserve el capital natural y cultural de Andalucía, con una oferta más diversificada que plantee

30 BERNAL, A. M. Turismo y desarrollo regional en Andalucía. Sevilla: Instituto de Desarrollo Regional de la Universidad de Sevilla, no 24, 1983, p. 59, 83, 194 y 245.

31 SECRETARÍA de Estado de Comercio y Turismo e Instituto de Estudios Turísticos. 25 años del turismo español en cifras. Madrid: SECT/IET, 2004, p. 6. 
estrategias para el desarrollo de un modelo de turismo sostenible. En el ámbito administrativo destaca como principal novedad la creación en la nueva Consejería de Turismo, Comercio y Deporte de la Dirección General de Calidad, Innovación y Prospectiva Turística, nacida con el fin de reforzar las políticas de calidad y los instrumentos de análisis de la evolución del turismo andaluz.

Hasta el momento los principales esfuerzos se han dirigido más a la promoción de la actividad turística que a la planificación, realizándose campañas que difunden la variedad paisajística y cultural de la región y que en cierta medida tratan de paliar la tradicional imagen caricaturizada y devaluada. En los últimos años se han diseñado diferentes propuestas que pretenden atender los nuevos gustos en las formas de hacer turismo. La Web Oficial del Turismo Andaluz de la Junta de Andalucía, además de la clásica oferta de sol y playa, habla del turismo rural y su creciente expansión, mencionando también las infraestructuras para el turismo de salud en balnearios, clínicas; las instalaciones deportivas existentes (estaciones de esquí, campos de golf, caza, pesca o hípica entre otras), o el de Congresos. Asimismo, se ofrecen una serie de itinerarios culturales siguiendo diferentes criterios: Arte y Patrimonio (rutas de la Andalucía americana a través de la arquitectura, de la Andalucía Antigua, del Barroco, Islámica, Renacentista, Romántica, de Castillos y Monasterios, de Obras Maestras de Pintura y Escultura, de la Arquitectura del Siglo XX, y del Gótico y Mudéjar); Costumbres y Tradiciones Populares (Andalucía Mágica, Taurina, Arquitectura Popular, Artesanía, Fiestas Populares, Jardines, Paisajes); y otras de interés como la Bética Romana, la del Tempranillo o el Legado Andalusí. ${ }^{32}$

Gracias a estas campañas, numerosas áreas rurales, ciudades y pueblos andaluces que estaban excluidos del flujo turístico, están consiguiendo dinamizar sus economías con la apertura de establecimientos destinados a atender la amplia demanda de servicios que generan estas nuevas modalidades de actividad turística. Un ejemplo de ello lo tenemos en Jerez de la Frontera, ciudad que años atrás contaba con un escaso turismo que por lo general pernoctaba en localidades costeras y se trasladaba una mañana para visitar alguna de sus famosas bodegas. En la actualidad, y tras una intensa campaña propagandística que destaca sus principales atri-

32 Al respecto consultar la Web Oficial del Turismo Andaluz: www.andalucia.org/modulos.php?modulo=Index 
butos (el vino, el caballo, el flamenco, el motociclismo...), 33 ha conseguido atraer un importante número de visitantes que se aloja en los numerosos establecimientos hoteleros que se han ido abriendo en el transcurso de los últimos años.

No obstante, el desarrollo de la actividad turística lleva aparejada efectos negativos, entre los que destacan el aumento de la especulación inmobiliaria con niveles preocupantes en la Costa del Sol, la desorganización de la vida tradicional, la desaparición de la agricultura en el litoral o el incremento de los problemas de conservación de los recursos naturales y patrimoniales de la región, entre muchos otros.

En lo que respecta a los centros históricos de las ciudades andaluzas, estos han experimentado en muchos casos importantes transformaciones, con la restauración de sus edificios más emblemáticos y la dotación de mejores infraestructuras y mobiliario urbano que les han hecho más atractivos de cara al fomento de la actividad turística. No obstante, la especulación urbana ha originado en muchos casos la expulsión de sus tradicionales moradores a los extrarradios de las ciudades y su sustitución por otros de mayor poder adquisitivo, aspecto que priva a estos espacios de uno de sus mayores atractivos, el legado cultural de sus vecinos que sienten el barrio como suyo. La Judería de Córdoba o el barrio de Santa Cruz en Sevilla se han convertido en espacios masificados por grupos de turistas que se agolpan por sus estrechas calles, contemplando edificios por lo general solitarios, tiendas de souvenir o espectáculos turísticos de flamenco.

Algunas actuaciones desarrolladas en el centro histórico de Cádiz o de Granada están consiguiendo sentar las bases para que los vecinos permanezcan en sus viviendas rehabilitadas, mientras que otras como Sevilla empiezan ahora a aplicar algunas de las medidas de este tipo con la apertura de una oficina destinada a asesorar y atender las demandas que los residentes del centro histórico les hagan en materia de vivienda. También son positivas las campañas destinadas a difundir los valores del patrimonio cultural andaluz entre los propios andaluces mediante la celebración de exposiciones, congresos y cursos, con una inversión importante en educación de fondo que ha conseguido disminuir los elevados niveles de analfabetismo que la región tenía escasas décadas atrás. No obstante, los retos y las incertidumbres de cara al futuro del sector turístico siguen siendo muchas.

33 RUIZ BALLESTEROS, Esteban: Construcción simbólica de la ciudad: política local y localismos. Madrid: Miño y Dávila Editores, 2000, p. 112-149. 


\section{Conclusiones}

Las experiencias andaluzas en la gestión del patrimonio cultural de sus ciudades, en lo que concierne al trato con la pobreza, la exclusión y la marginalidad social, con la degradación del medio urbano y las tensiones entre los diversos usos y actividades que afectan negativamente el medio social y físico edificado, pueden servir como referentes de interés para la revitalización de los centros históricos de Salvador y de Recife. Entre ellas destacan algunas como las puestas en práctica en Granada, uno de los principales destinos turísticos urbanos de Andalucía.

El Instituto Municipal de Rehabilitación de dicha ciudad, con subsidios de la Unión Europea, de la Junta de Andalucía y del Ayuntamiento de Granada, desenvolvieron una serie de estrategias destinadas a conseguir la rehabilitación del Barrio del Bajo Albaicín. Se buscaba entonces revalorizar el patrimonio arquitectónico, mejorar las condiciones de vida de la población residente, favorecer la manutención de la población en peores condiciones socio-económicas y potenciar el desenvolvimiento económico y social del barrio. Para eso, se consideró prioritario valorizar el patrimonio residencial, crear una cultura de conservación y rehabilitación de la ciudad, condición imprescindible para preservarla y convertirla en un lugar lleno de vida.

Instituyó entonces programas ambientales de mejoramiento de los espacios degradados, concediendo ayuda financiera a los residentes y propietarios para la rehabilitación y reconstrucción de fachadas y tejados de los inmuebles. Otra estrategia fue la subvención de acciones para la mejora de las viviendas situadas en inmuebles cuyo destino principal fuese la residencia habitual y permanente. Una de las principales metas consistió en eliminar las situaciones de infravivienda, invirtiendo en el alojamiento de personas en situaciones socioeconómicas difíciles. Se crearon viviendas de promoción pública con alquiler subsidiados y centros de recreación y ocio para el mantenimiento de la población residente y su integración social. ${ }^{34}$

34 INSTITUTO Municipal de Rehabilitación/Ayuntamiento de Granada. Vivir en la ciudad histórica. Granada: Encuadernaciones Olmedo, 2003. 
cas, deben tener en cuenta los valores culturales locales y orientar los criterios de calidad para satisfacer al turista y preservar el destino turístico. ${ }^{36}$

Esperamos que esas ciudades sean capaces de elaborar planos de gestión de su patrimonio cultural, orientados por los principios de una nueva postura ética, aprendida del concepto de desenvolvimiento sustentable, y que considere la multidimensionalidad de la sociedad en sus aspectos económico, político, social, ambiental y cultural.

Solamente así se crearán mecanismos de concertación de ideas y prácticas para hacer converger valores y concentrar acciones que, en suma, promuevan la conservación integrada del patrimonio cultural.

36 CALLE VAQUERO, La ciudad..., p. 20. 